\title{
SIMILARIDADE GENÉTICA ENTRE ACESSOS DE GOIABEIRAS E ARAÇAZEIROS BASEADA EM MARCADORES MOLECULARES AFLP ${ }^{1}$
}

\author{
LUIZ CLAUDIO CORRÊA ${ }^{2}$, CARLOS ANTONIO FERNANDES SANTOS ${ }^{3}$, \\ GIUSEPPINA PACE PEREIRA LIMA ${ }^{4}$, MARCIENE AMORIM RODRIGUES 5 , \\ TUANY PRISCILA PEREIRA COSTA ${ }^{6}$
}

RESUMO-Espécies do gênero Psidium, como goiabeira e araçazeiros, são economicamente importantes e têm como área de diversidade genética primária o Brasil. Foram determinadas as relações genéticas, com base no marcador AFLP, para acessos do Banco Ativo de Germoplasma (BAG) de Psidium da Embrapa Semiárido, para orientar trabalhos de melhoramento e de manejo de recursos genéticos do gênero. Foram analisados 88 acessos, sendo 64 de goiabeira e 24 de araçazeiros, coletados em dez Estados brasileiros, adotando-se para agrupamento o dendrograma UPGMA, considerando a matriz de similaridade do coeficiente de Jaccard de 149 bandas polimórficas de AFLP de 16 combinações dos iniciadores EcoRI e MseI. A análise da variância de dados moleculares foi realizada considerando a variação entre e dentro das populações de goiabeira dos dez Estados. O dendrograma apresentou boa definição, com coeficiente de correlação cofenética de 0,94 . Foram observados dois grandes grupos: um formado por acessos de goiabeira e outro com acessos de araçazeiros, com inclusão de alguns acessos de goiabeira. Foram observados agrupamentos específicos no dendograma apenas para os indivíduos de goiabeira coletados em Goiás e Roraima. Os acessos estudados apresentaram similaridade variando de 28 a 98\%, evidenciando a alta variabilidade genética dos mesmos. A variação entre acessos foi estimada em $0,16\left(\phi_{S T}\right)$, indicando diferenciação genética moderada entre as populações de goiabeira dos dez Estados. Para aumentar a variabilidade genética do BAG estudado, sugere-se a coleta de um número maior de acessos nos Estados de Goiás e Roraima, dado o alto índice de similaridade entre os acessos provenientes destes Estados, bem como coletas amplas em outros Estados brasileiros. Sugeremse ainda cruzamentos entre os poucos acessos de goiabeira posicionados no grupo dos araçazeiros para o desenvolvimento de híbridos interespecificos no gênero Psidium.

Termos para indexação: Psidium, banco ativo de germoplasma, melhoramento vegetal, AMOVA.

\section{GENETIC SIMILARITY AMONG ACCESSIONS OF GUAVA AND BRAZILIAN GUAVA ARAÇAZEIROS BASED ON AFLP MARKERS}

\begin{abstract}
Species of the genus Psidium, like guava and Brazilian guava trees, are economically important and have the area of primary genetic diversity in Brazil. It was determined the genetic relationships based on AFLP marker for accessions of Psidium Germplasm Bank (PGB) of Embrapa Semiarid to guide improvements and management of genetic resources of the genus. Eighty-eight accessions were analyzed, 64 of guava and 24 of Brazilian guava, collected in ten Brazilian States, adopting for the cluster dendrogram UPGMA, considering the similarity matrix of Jaccard's coefficient of 149 polymorphic AFLP bands from 16 combinations of primers EcoRI and MseI. Analysis of variance of molecular data was performed considering the variation between and within populations of guava from the ten states. The dendrogram showed good definition, with cophenetic coefficient of 0.94 . Two major groups were identified: one formed by accessions of guava and other with access to Brazilian guava, including some accessions of guava. Specific groups were observed in the dendrogram only for individuals guava collected in Goias and Roraima. These accessions showed similarity ranging from 28 to $98 \%$, suggesting a high genetic variability of them. The variation among accessions was estimated at $0.16\left(\phi_{S T}\right)$, indicating moderate genetic differentiation among guava populations from the ten states. To increase the genetic variability of the ABG studied, it is suggested to collect more hits in the states of Goiás and Roraima, due to the high degree of similarity among accessions from these states, as well as extensive collections in other Brazilian states. Crosses among the few accessions of guava which are positioned in the group of Brazilian guava were also suggested for the development of interspecific hybrids in the genus Psidium.
\end{abstract}

Index terms: Psidium, germplasm collection, plant breeding, AMOVA.

\footnotetext{
${ }^{1}$ (Trabalho 213-10). Recebido em: 25-10-2010. Aceito para publicação em: 23-3-2011.

${ }^{2}$ Doutor em Fisiologia Vegetal, Universidade Estadual Paulista, Caixa Postal 510, 18618-970, Botucatu- SP. E-mail: ccorrea@ibb.unesp.br ${ }_{3}^{3}$ Pesquisador da Embrapa Semi-Árido. Caixa Postal 23, 56302-970, Petrolina- PE. E-mail: casantos@cpatsa.embrapa.br ${ }^{4}$ Professora da Universidade Estadual Paulista, Caixa Postal 510, 18618-970, Botucatu- SP. E-mail: gpplima@ibb.unesp.br ${ }^{5}$ Mestranda em Biotecnologia/ Universidade Estadual de Feira de Santana, 44036-900, Feira de Santana- BA. E-mail: eninharodrigues@hotmail.com

${ }^{6}$ Mestranda em Recursos Genéticos Vegetais/ Universidade Federal do Recôncavo da Bahia, 44380-000, Cruz das Almas- BA. E-mail: tuanypriscila@hotmail.com
} 


\section{INTRODUÇÃO}

A goiabeira e o araçazeiro pertencem à família Myrtaceae, que compreende aproximadamente 130 gêneros e 3.000 espécies de árvores e arbustos distribuídos principalmente nos trópicos e subtrópicos (WATSON; DALLWITS, 2010). Essas espécies são de grande importância para o Brasil, pois o gênero Psidium, ao qual pertencem a goiabeira e os araçazeiros, é Neotropical com distribuição nativa do sul do México até Buenos Aires, na Argentina (SOARES-SILVA; PROENÇA, 2008). Ainda segundo Risterucci et al. (2005), a goiabeira é nativa do norte da América do Sul e largamente distribuída nas regiões tropicais das Américas.

O cultivo da goiabeira ganha espaço devido a características apreciáveis do seu fruto, como sabor, aspecto e riqueza em nutrientes e elementos funcionais, além de poder ser consumida in natura ou nas formas de doces, geleias, compotas, sucos, dentre outras (SÃO JOSÉ et al., 2003). Já o araçazeiro, apesar de não apresentar a mesma importância econômica, tem sido estudado como alternativa de plantio comercial em algumas regiões, ou mesmo como potencial porta-enxerto (SOUZA et al., 2006).

O melhoramento genético é uma potente ferramenta, tanto no que diz respeito à obtenção de cultivares com vantagens econômicas, quanto na caracterização e conservação de material genético. Um recurso utilizado neste campo são os bancos ativos de germoplasma (BAGs) que, além de propiciarem a conservação do material, servem como fontes para estudos dos caracteres morfológicos, nutricionais, funcionais e genéticos, assim como de marcadores moleculares.

Estudos de variação genética têm sido realizados através de caracteres fenotípicos, que são frequentemente influenciados por condições ambientais (PERSSON, 2001). Diante disso, trabalhos com esse objetivo passaram a ser complementados, nas últimas décadas, por técnicas moleculares (KUMAR, 1999). O conhecimento de marcadores moleculares pode auxiliar, tanto em estudos de mapeamento genético como na identificação de híbridos de interesse nas gerações de indivíduos e na seleção de potenciais portaenxertos. Segundo Santos et al. (2007), informações obtidas com marcadores possibilitam a definição de estratégias para conservação de recursos genéticos.

Diversos estudos de caracterização de goiabeiras e/ou araçazeiros, tanto nativos como introduzidos em BAGs, foram realizados com o uso de marcadores moleculares, (HERNÁNDEZ-DELGADO et al., 2003; REVELES et al., 2003; RUEDA et al., 2003; SANABRIA et al., 2006).
Erig et al. (2003), avaliando a diversidade genética entre 24 acessos de araçazeiros por meio de RAPD, separaram os genótipos em 4 grupos, sendo que o primeiro apresentou $40 \%$ de similaridade com os demais, ao passo que a maior proximidade foi encontrada entre os 2 últimos (73\%).

Marcadores SSR foram utilizados na caracterização de 34 acessos de goiaba de uma coleção cubana (VALDÉS-INFANTE et al., 2007). Neste estudo, 7 pares de primers específicos geraram 34 diferentes alelos, dentre os quais, 10 considerados raros. Após o processamento dos dados, os acessos foram separados em 6 grupos, além de dois acessos isolados.

AFLP (amplified fragment length polymorphism) é um marcador molecular muito utilizado na caracterização genética, permitindo a detecção de alto número de polimorfismos. Valdés-Infante et al. (2003) analisaram 62 acessos de goiabas de um BAG de Cuba através do marcador AFLP, não detectando separação evidente entre os provenientes da Flórida e das Ilhas Seychelles, os quais foram ali introduzidos.

Este marcador foi também utilizado por Hernández-Delgado et al. (2007), na análise de 52 acessos de Psidium de uma coleção mexicana, cujo dendrograma gerou dois grupos principais, sendo o primeiro, composto por acessos de $P$. cattleianum e $P$. friedrichsthalianum, e o segundo, por acessos de P. guajava. Acessos do BAG da Embrapa Semiárido foram recentemente caracterizados com relação a aspectos morfológicos (SANTOS et al., 2008a).

O objetivo deste trabalho foi estudar a variabilidade genética de acessos de goiabeiras e araçazeiros do Banco Ativo de Germoplasma da Embrapa Semiárido, com base no marcador AFLP, a fim de fornecer subsídios para programas de melhoramento do gênero Psidium.

\section{MATERIAL E MÉTODOS}

Foram analisados 64 acessos de goiabeira e 24 de araçazeiros do BAG da Embrapa Semiárido, em Petrolina-PE, provenientes de 10 Estados do Brasil: Amazonas, Bahia, Goiás, Maranhão, Pernambuco, Piauí, Rio Grande do Sul, Rondônia, Roraima e Sergipe, além de duas cultivares comerciais de goiaba (Paluma e Pedro Sato) (Tabela 1).

O DNA foi extraído segundo método proposto por Doyle e Doyle (1990), com as seguintes modificações: a primeira e a segunda centrifugações foram realizadas a 6.000 e $10.000 \mathrm{rpm}$, respectivamente; foi utilizado $\beta$-mercaptoetanol a $2 \%$. Após tratamento com RNase, foi utilizado gel de agarose para a verificação da integridade e da quantificação 
do DNA extraído, seguindo-se da diluição da solução para $40 \mathrm{ng} \mu \mathrm{L}^{-1}$.

O DNA (200 ng) foi digerido com as endonucleases EcoRI e MseI ( 0,62 unidades cada), por $2 \mathrm{~h}$ 30. A ligação/adaptação foi realizada com a enzima T4 DNA ligase, seguida de diluição (1:5). A reação de pré-amplificação foi realizada utilizando-se de $1,5 \mu \mathrm{M}$ do iniciador EcoRI, $1,5 \mu \mathrm{M}$ do iniciador MseI, 0,2 mM de cada dNTPs, 1x de tampão PCR (100 mM Tris- $\mathrm{HCl} \mathrm{pH} 8,3,500 \mathrm{mM} \mathrm{KCl}$ ), 2,5 mM $\mathrm{MgCl}_{2}, 0,75$ unidades de Taq DNA Polimerase, 2, $0 \mu \mathrm{L}$ de solução de DNA ligado, para volume final de $15 \mu \mathrm{L}$. A programação do termociclador para amplificações pré-seletivas consistiu em 20 ciclos a $94^{\circ} \mathrm{C}$, durante 30 segundos, $56^{\circ} \mathrm{C}$ por 1 minuto e $72^{\circ} \mathrm{C}$ durante 1 minuto.

Para a reação de amplificação, o DNA préamplificado foi diluído 20 vezes em água ultrapura. A reação de PCR foi então realizada, utilizando-se de $0,2 \mu \mathrm{M}$ do iniciador da EcoRI, $0,3 \mu \mathrm{M}$ do iniciador da MseI, 0,2 mM de dNTPs, 1x tampão de PCR (100 $\mathrm{mM}$ Tris-HCl pH 8,3 e $500 \mathrm{mM} \mathrm{KCl}), 2,5 \mathrm{mM}$ de $\mathrm{MgCl}_{2}, 0,5$ unidade de Taq DNA polimerase e $2 \mu \mathrm{L}$ do DNA pré-amplificado e diluído, completando-se o volume para $10 \mu \mathrm{L}$ com água ultrapura. A programação do termociclador consistiu em um ciclo a $94^{\circ} \mathrm{C}$, por 1 minuto, seguido de $65^{\circ} \mathrm{C}$ durante 30 segundos e $72^{\circ} \mathrm{C}$ por 1 minuto, repetidos 13 vezes e com a temperatura de anelamento $\left(65^{\circ} \mathrm{C}\right)$ decaindo $0,7^{\circ} \mathrm{C}$ para o ciclo subsequente; 23 ciclos a $94^{\circ} \mathrm{C}$, por 30 segundos, $56^{\circ} \mathrm{C}$ por 30 segundos e $72^{\circ} \mathrm{C}$ durante 1 minuto. Às reações, foram adicionados $5 \mu \mathrm{L}$ de formamida, seguindo-se de aquecimento da placa por 3 minutos a $94^{\circ} \mathrm{C}$ e aplicação em gel de poliacrilamida a $6 \%$. A visualização dos fragmentos nos géis de poliacrilamida foi realizada por impregnação com nitrato de prata, conforme descrito por Creste (2001).

Foram utilizadas 16 combinações de primers e anotadas as bandas polimórficas para cada combinação, adotando-se " 1 " para presença, " 0 " para ausência e "9" para falha na reação de PCR. Para a construção da matriz de similaridade, adotou-se o índice de Jaccard, confeccionando-se o fenograma pelo método de agrupamento UPGMA (Método de Agrupamento não Ponderado com Base na Média Aritmética), disponível no programa NTSYS. A avaliação do ajuste do fenograma foi realizada pela correlação cofenética, ou seja, entre as distâncias reais e representadas graficamente.

A análise da variância de dados moleculares (AMOVA) foi realizada pela decomposição total nas suas componentes entre e dentro de acessos, utilizando-se das distâncias ao quadrado, conforme descrito por Excoffier et al. (1992), com o auxílio do programa GenAlEx (PEAKALL; SMOUSE, 2006). A significância destas estimativas foi obtida pelo método de randomização, utilizando 999 permutações. A interpretação do parâmetro é similar à estatística $\mathrm{F}$ de Wright (1951), considerando que não há diferenciação genética quando $\mathrm{F}=0$ e que há fixação dos alelos alternativos e grande diferenciação entre populações quando $\mathrm{F}=1$.

\section{RESULTADOS E DISCUSSÃO}

Foi obtido um total de 149 fragmentos polimórficos nas 16 combinações de primers (CP) EcoR1/Msel de AFLP nos 88 acessos de Psidium, com média de 9,3 fragmentos/CP. (19) (Tabela 2), sendo anotadas apenas as bandas bem definidas. A media de 10 fragmentos polimórficos de AFLP foi reportada por Santos et al. (2008b), usando coloração com nitrato de prata, o que é muito próximo ao obtido neste trabalho. Hernández-Delgado et al. (2007) relatam a surpreendente média de 79,5 fragmentos polimórficos de AFLP numa coleção mexicana com 52 acessos de Psidium.

Dentre os fragmentos, foi possível identificar 13 e 31 que ocorreram em menos de $30 \%$ dos acessos de araçazeiros e de goiabeiras, respectivamente. Observou-se ainda a ocorrência de três fragmentos presentes em mais de $70 \%$ dos acessos de araçazeiros e em menos de $30 \%$ das goiabeiras, além de seis fragmentos que ocorreram em $70 \%$ das goiabeiras, porém em menos de $30 \%$ dos araçazeiros (Tabela 2).

Em estudo de caracterização de 34 acessos de uma coleção cubana utilizando marcadores SSR, Valdés-Infante et al. (2007) encontraram 34 diferentes alelos, dentre os quais, 10 considerados raros. Após processamento dos dados, os acessos foram separados em 6 grupos, além de dois acessos isolados.

A existência de fragmentos raros, que ocorrem em uma porcentagem muito pequena dos acessos, pode conferir alguma vantagem adaptativa aos mesmos, o que é importante para propostas de reprodução e conservação (VALDÉS-INFANTE et al., 2007).

O coeficiente de correlação cofenética foi de 0,94 , indicando que o dendrograma produzido foi uma boa representação dos 149 fragmentos de AFLP. O dendrograma mostra a separação dos acessos em dois grupos: grupo 1, de GUA01MA até GUA58SE, e grupo 2, de GUA14MA até ARA93AM (Figura 1). O grupo 1, formado exclusivamente por acessos de goiabeira, pode ser subdividido em dois outros subgrupos: subgrupo 1.1, de GUA01MA até GUA49SE, e subgrupo 1.2, de GUA04MA até GUA58SE. O 
grupo 2 foi formado principalmente por acessos de araçazeiros, sendo que dos oito acessos de goiabeira entre os 24 acessos de araçazeiros, quatro foram coletados no Estado do Maranhão, indicando que os acessos desse Estado são os que apresentam maior similaridade com espécies de araçazeiros.

Erig et al. (2003), avaliando a diversidade genética entre 24 acessos de araçazeiros por meio de RAPD, separaram os genótipos em 4 grupos, sendo que o primeiro apresentou $40 \%$ de similaridade com os demais, ao passo que a maior proximidade foi encontrada entre os 2 últimos (73\%).

$\mathrm{O}$ acesso ARA93AM apresentou a menor similaridade em relação ao conjunto dos acessos avaliados, enquanto a maior similaridade foi observada entre os acessos GUA128GO e GUA$131 \mathrm{GO}$, coletados nas cidades goianas de Mimoso de Goiás e Alto Paraíso. As cultivares Pedro Sato e Paluma posicionaram-se em ramos contínuos do dendrograma, com similaridade genética em torno de $84 \%$ (Figura 1). Os acessos de goiabeira coletados no Estado de Goiás e em Roraima, no grupo 1 , posicionaram-se quase que sequencialmente nos ramos do dendrograma, sugerindo uma grande similaridade genética entre os mesmos. Os quatro acessos de araçazeiros coletados no Estado do Rio Grande do Sul apresentaram idêntico agrupamento, concentrando-se próximos da base do dendrograma, indicando grande similaridade entre eles. Hernández-Delgado et al. (2007) encontraram o mesmo padrão de separação entre acessos mexicanos de goiabeira e outras espécies de Psidium, como $P$. cattleianum e $P$. friedrichsthalianum avaliados com marcadores AFLP.
Os acessos de Psidium avaliados apresentaram similaridade variando de 0,28 a 0,98 , evidenciando a alta variabilidade genética da coleção de germoplasma estudada (Figura 1 e Tabela 1). Valdés-Infante et al. (2007) encontraram similaridade variando de 0,17 a 0,96 entre 40 acessos de uma coleção cubana de goiabeira avaliada com oito marcadores microssatélites. Alta variabilidade genética foi também reportada por Hernández-Delgado et al. (2007) entre 52 acessos de uma coleção mexicana de Psidium avaliada com marcador AFLP. No geral, esses resultados indicam a presença de alta variabilidade genética na goiabeira, $\mathrm{o}$ que pode ser favorecido pelo sistema misto de acasalamento da goiabeira, que inclui tanto a autofecundação como a polinização cruzada entre plantas da espécie.

A estimativa da variação entre os 62 acessos de goiabeira dos dez Estados foi de 0,16 $\left(\phi_{S T}\right)$, sendo a diferenciação genética considerada como moderada. Esta estimativa sugere que essa espécie possui fluxo gênico moderado, com a variabilidade maior dentro do que entre os acessos dos dez Estados (Tabela 3 ), o que pode ocorrer em espécies que apresentam sistema misto de acasalamento. Hernández-Delgado et al. (2007) reportaram alta diferenciação genética entre acessos de Psidium $\left(\phi_{S T}=0,375\right)$, o que deve ter sido influenciado pela análise conjunta de goiabeira e araçazeiros. Sanabria et al. (2006) reportaram, também, alta diferenciação genética entre 53 acessos de nove populações de goiabeiras colombianas $\left(\phi_{S T}\right.$ $=0,355)$ avaliadas com 74 marcadores polimórficos de RAPD. Os resultados indicam que existe variação estratificada para os acessos de goiabeira coletados nos Estados de Goiás e Roraima, pois os mesmos formaram agrupamentos próprios no dendrograma (Figura 1), enquanto os acessos dos demais Estados foram agrupados independentemente do seu local de coleta. 
TABELA 1 - Procedência dos acessos de goiabeira (G) e araçazeiro (A) do banco ativo de germoplasma da Embrapa Semiárido.

\begin{tabular}{|c|c|c|c|c|c|}
\hline Acesso & Procedência & Estado & Acesso & Procedência & Estado \\
\hline G01 MA & Caxias & MA & G84AM & Itacoatiara & $\overline{A M}$ \\
\hline G03 MA & Coelho Neto & MA & G86 AM & Iranduba & AM \\
\hline G04 MA & Buriti & MA & A93 AM & Autazes & $\mathrm{AM}$ \\
\hline G06 MA & Mata Roma & MA & G94AM & Autazes & $\mathrm{AM}$ \\
\hline A08 MA & Mata Roma & MA & G96 AM & Autazes & $\mathrm{AM}$ \\
\hline G10 MA & Presidente Vargas & MA & G99AM & Autazes & $\mathrm{AM}$ \\
\hline G12 MA & Cajari & MA & A102 RS & Pelotas & $\mathrm{RS}$ \\
\hline G13 MA & Viana & MA & A103 RS & Pelotas & $\mathrm{RS}$ \\
\hline G14 MA & Pindari & MA & G104 RS & Pelotas & $\mathrm{RS}$ \\
\hline G16 MA & Bom Jardim & MA & A105 RS & Pelotas & $\mathrm{RS}$ \\
\hline G18 MA & Santa Luzia & MA & G106 RS & Pelotas & $\mathrm{RS}$ \\
\hline G19 MA & Graiaú & MA & A107 RS & Pelotas & $\mathrm{RS}$ \\
\hline G21 MA & Tuntum & MA & A108 RS & Pelotas & $\mathrm{RS}$ \\
\hline G23 MA & Presidente Dutra & MA & G109 RS & Pelotas & $\mathrm{RS}$ \\
\hline G25 MA & Colinas & MA & G111 GO & Vianópolis & GO \\
\hline G26 MA & Paraibano & MA & G113 GO & Vianópolis & GO \\
\hline G28 PI & Colônia Gurqueia & PI & G116 GO & Morrinhos & GO \\
\hline A29 PI & Eliseu Martins & PI & G118 GO & Prof. Jamil & GO \\
\hline G30 PI & Canto do Buriti & PI & G120 GO & Goiás Velho & GO \\
\hline G31 PI & Brejo do Piauí & PI & G121 GO & Goiás Velho & GO \\
\hline G32 PE & Ibimirim & PE & A122 GO & Goiás Velho & GO \\
\hline A44 PE & Escada & $\mathrm{PE}$ & A123 GO & Goiás & GO \\
\hline G58 SE & Santa Luzia & $\mathrm{PE}$ & G125 GO & Santa Isabel & GO \\
\hline G38 PE & Pesqueira & $\mathrm{PE}$ & G127 GOI & Mimoso de Goiás & $\mathrm{GO}$ \\
\hline G40 PE & Gravatão & $\mathrm{PE}$ & G128 GOI & Mimoso de Goiás & $\mathrm{GO}$ \\
\hline A42 PE & Escada & $\mathrm{PE}$ & G130 GO & Áqua Fria & $\mathrm{GO}$ \\
\hline A43 PE & Escada & $\mathrm{PE}$ & G131 GO & Alto Paraíso & GO \\
\hline G46 PE & Escada & $\mathrm{PE}$ & G133 RR & Iracema & $\mathrm{RR}$ \\
\hline G47 PE & Riacho das almas & $\mathrm{PE}$ & G135 RR & Iracema & $\mathrm{RR}$ \\
\hline G49 SE & Dores & SE & G136 RR & Rorainópolis & $\mathrm{RR}$ \\
\hline G51 SE & Capela & SE & G137 RR & Caracaraí & $\mathrm{RR}$ \\
\hline G53 SE & Japoratuba & SE & A138 RR & Boa Vista & $\mathrm{RR}$ \\
\hline A56 SE & Santa Luzia & SE & A139 RR & Boa Vista & $\mathrm{RR}$ \\
\hline A57 SE & Santa Luzia & SE & G141 RR & Alto Aleqre & $\mathrm{RR}$ \\
\hline A63 BA & Antonio Gonçalos & BA & G142 RR & Alto Aleqre & $\mathrm{RR}$ \\
\hline G33 PE & Ibimirim & $\mathrm{PE}$ & G145 BA & Valença & $\mathrm{BA}$ \\
\hline G66 RO & Ouro Preto do Oeste & $\mathrm{PE}$ & G147 BA & Taperoá & $\mathrm{BA}$ \\
\hline G67 RO & Jaru & $\mathrm{RO}$ & A149 BA & Taperoá & BA \\
\hline G69 RO & Buritis & RO & G150 BA & Nilo Peçanha & BA \\
\hline G71 RO & Monte Neqro & RO & A152 BA & Ituberá & BA \\
\hline G73 RO & Ariauemes & RO & A $153 \mathrm{BA}$ & Ituberá & $\mathrm{BA}$ \\
\hline A76 RO & Alto Paraíso & RO & A154 BA & Iqrapiúna & $\mathrm{BA}$ \\
\hline A79 RO & Porto Velho & RO & G-- PE & Comercial & $\mathrm{PE}$ \\
\hline G82 RO & Porto Velho & RO & $\mathrm{G} \quad \mathrm{PE}$ & Comercial & $\mathrm{PE}$ \\
\hline
\end{tabular}

MA: Maranhão; PI: Piauí; Pe: Pernambuco; BA: Bahia; RO: Rondônia; RR: Roraima; GO: Goiás; AM: Amazonas; RS: Rio Grande do Sul.; G--PE: cv. Pedro Sato e G__PE: cv. Paluma. 
TABELA 2 - Combinações de primers AFLP utilizadas, número e frequência de fragmentos nos 88 acessos de Psidium do BAG da Embrapa Semiárido.

\begin{tabular}{cccccccc}
\hline Primers & nfp & fa & fg & ra & rg & farg & fgra \\
\hline AAG/CAG & 10 & 5 & 6 & 0 & 1 & 1 & 0 \\
AAG/CAT & 19 & 2 & 8 & 0 & 6 & 0 & 0 \\
AAG/CTC & 6 & 2 & 6 & 1 & 0 & 0 & 1 \\
ACA/CAC & 12 & 6 & 8 & 1 & 2 & 1 & 0 \\
ACA/CTG & 9 & 6 & 7 & 0 & 1 & 0 & 0 \\
ACC/CAG & 9 & 0 & 3 & 1 & 1 & 0 & 1 \\
ACT/CAA & 7 & 1 & 11 & 3 & 1 & 0 & 3 \\
ACT/CAA & 6 & 1 & 4 & 1 & 1 & 0 & 0 \\
ACT/CAT & 10 & 1 & 4 & 1 & 4 & 0 & 1 \\
AGC/CAA & 6 & 1 & 2 & 0 & 3 & 0 & 0 \\
AGC/CAG & 12 & 2 & 5 & 1 & 4 & 0 & 0 \\
AGC/CAT & 10 & 4 & 4 & 0 & 0 & 1 & 0 \\
AGC/CTA & 7 & 1 & 3 & 0 & 2 & 0 & 0 \\
AGC/CTC & 8 & 2 & 4 & 3 & 3 & 0 & 0 \\
AGG/CAC & 8 & 5 & 6 & 1 & 1 & 0 & 0 \\
ACT/CAG & 10 & 5 & 6 & 0 & 1 & 0 & 0 \\
\hline Total & 149 & 44 & 87 & 13 & 31 & 3 & 6 \\
\hline
\end{tabular}

nfp: número de fragmentos polimórficos; fa e fg: fragmentos frequentes- presentes em mais de $70 \%$ dos araçazeiros (fa) e goiabeiras (fg); ra e rg: fragmentos raros- presentes em menos de $30 \%$ dos araçazeiros (ra) e goiabeiras (rb); farg: fragmentos frequentes em araçás e raros em goiabas (presentes em mais de $70 \%$ dos araçazeiros e menos de $30 \%$ das goiabeiras); fgra: presentes em mais de $70 \%$ das goiabeiras e menos de $30 \%$ dos araçazeiros.

TABELA 3 - Análise de variância molecular (AMOVA) para 62 acessos de Psidium, coletados em dez Estados brasileiros e avaliados com 149 marcas de AFLP.

\begin{tabular}{lccccc}
\hline Fonte de variação & GL & SQ & Total da variação (\%) & $\mathrm{P}^{2}$ & Estatística $\phi$ \\
\hline Entre Acessos & 09 & 289,7 & 16 & $(<0,001)$ & $\phi \mathrm{ST}=0,16$ \\
Dentro de Acessos & 52 & 784,6 & 84 & $(<0,001)$ & $1-\phi \mathrm{ST}=0,84$ \\
\hline TOTAL & 61 & 1074,3 & 100 & & \\
\hline
\end{tabular}

${ }^{2}$ probabilidade baseada em 999 permutações. 


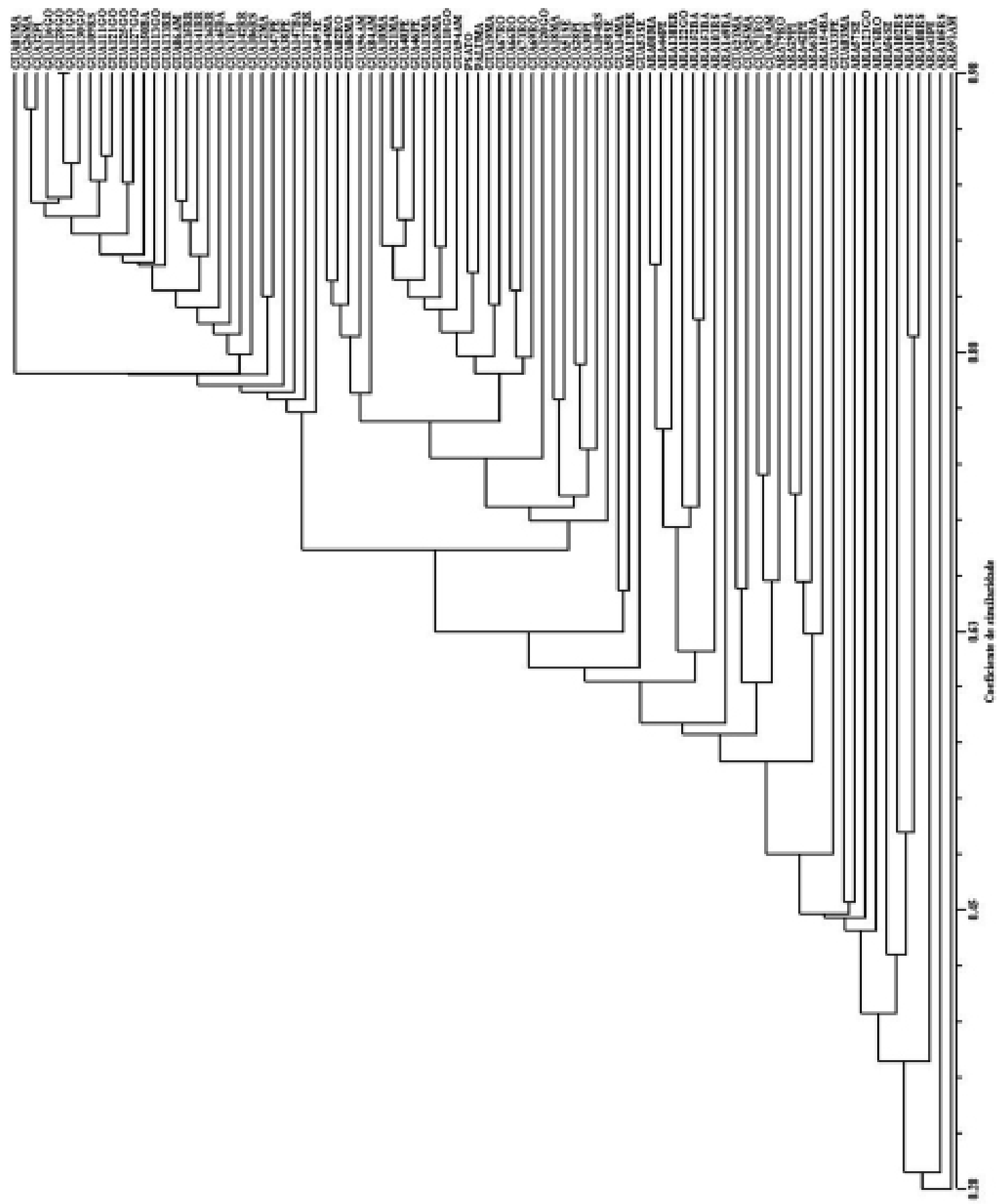

FIGURA 1 - Dendrograma UPGMA do coeficiente de Jaccard entre 64 acessos de goiabeiras e 24 de araçazeiros do BAG da Embrapa Semiárido, amostrados em 10 Estados brasileiros, analisados com 149 marcadores AFLP (EcoRI/Msel). Coeficiente de correlação cofenético = 0,94. 


\section{CONCLUSÕES}

1 - Os resultados indicam duas situações para o germoplasma de goiabeira brasileiro: a) os acessos têm sido artificialmente propagados de um local para outro, como indicado para o germoplasma de oito dos dez Estados, enquanto b) os agrupamentos dos acessos provenientes de Goiás e Roraima indicam impedimentos para o livre intercâmbio de germoplasma para as demais regiões brasileiras.

2 - Devem ser realizadas coletas de germoplasma especificas para os Estados de Goiás e Roraima, e coletas amplas para um menor número de regiões dos outros Estados brasileiros para aumentar a variabilidade genética do germoplasma de Psidium no BAG mantido pela Embrapa Semiárido.

3 - Devem ser realizados cruzamentos entre os poucos acessos de goiabeira posicionados no grupo dos araçazeiros para o desenvolvimento de híbridos interespecíficos no gênero Psidium.

\section{REFERÊNCIAS}

CRESTE, S.; TULMANN NETO, A.; FIGUEIRA, A. Detection of Single Sequence Repeat Polymorphisms in Denaturing Polyacrylamide Sequencing Gels by Silver Staining. Plant Molecular Biology Reporter, Athens, v. 9, p.299-306, 2001.

DOYLE, J. J.; DOYLE, J. L. Isolation of plant DNA from fresh tissue. Focus, Rockville, v.12, p. 13-15, 1990.

ERIG, A. C.; SCHUCH, M.W.; RASEIRA, M. C. B.; VIGHI, I.L.; ROCHA, P. S. G.; WENDT, S. N. RAPD molecular marker in the evaluation of genetic diversity in araçazeiro. Revista Científica Rural, Bage, v. 8, n. 2, p. 101-106, 2003.

EXCOFFIER, L.; SMOUSE, P. E.; QUATTRO, J. M. Analysis of molecular variance inferred from metric distances among DNA haplotypes: application to human mitochondrial DNA restriction data. Genetics, Austin, v. 131, p. 479-491, 1992.

HERNÁNDEZ-DELGADO, S.; MARTÍNEZ, J.; PADILLA, S.; MAYEK, N. Diversidad genética de Psidium sp. em la región Calvillo- Cañonnes. In: SIMPOSIO INTERNACIONAL DE LA GUAYABA, 1., 2003. México. Anais... p. 71-83.
HERNÁNDEZ-DELGADO, S.; PADILLARAMÍREZ, J. S.; NAVA-CEDILLO, A.; MAYEKPÉREZ, N. Morphological and genetic diversity of Mexican guava germplasm. Plant Genetic Resources: Characterization and Utilization, Cambridge, v.5, n.3, p.131-141, 2007. Disponível em: <http://journals.cambridge.org/ action/displa yFulltext?type $=1 \&$ fid $=1433772 \&$ jid $=$ PGR\&volu meId $=5 \&$ issueId $=03 \&$ aid $=1433764>$. Acesso em: 25 jan. 2010.

KUMAR, L. S. DNA markers in plant improvement: An overview. Biotechnology Advances, New York, v.17, p.143-182, 1999.

PEAKALL, R.; SMOUSE, P. E. Genalex 6: genetic analysis in Excel Population genetic software for teaching and research. Molecular Ecology Notes, Oxford, v. 6, p. 288-295, 2006. Disponível em: $<$ http://www3.interscience.wiley.com/cgi-bin/ full $\rightarrow$ text/118613605/PDFSTART>. Acesso em: 25 jan. 2010.

PERSSON, H. Estimating genetic variability in horticultural crop species at different stages of domestication. 2001. 30 f. Thesis (Doctoral Crop Science) - Swedish University of Agricultural Sci $\neg$ ences, Uppsala, 2001.

PERSSON, H. Estimating genetic variability in horticultural crop species at different stages of domestication. 2001. 30 f. Thesis (Doctoral Crop Science) - Swedish University of Agricultural Sciences, Uppsala, 2001

REVELES, L. R.; SAENZ, L. A.; ESPARZA, E.; CABRAL, F. J. Polimorfismo de ADN ge $\neg$ nómico em 12 selecciones de guayabo (Psidium guajava L) del banco de germoplasma del campo experimental "Los Cañones". In: SIMPOSIO IN $\neg$ TERNACIONAL DE LA GUAYABA, 1., 2003. México. Anais... p.248-252.

RISTERUCCI, A. M. et al. Isolation and characterization of microsatellite loci from Psidium guajava L. Molecular Ecology Notes, Oxford, v. 5, p. 745748,2005

RISTERUCCI, A. M.; DUVAL, M. F.; W. ROHDE, W.; BILLOTTE, N. Isolation and character-ization of microsatellite loci from Psidium guajava L. Molecular Ecology Notes, Oxford, v. 5, p. 745- 748, 2005 . 
RUEDA, L. A.; MUÑOZ, J. E.; SAAVEDRA, R.; PALACIO, J. D.; BRAVO, E. Caracterización molecular del banco de germoplasma de guayaba (Psidium spp) del Centro de Investigación de Corpoica Palmira. In: SEMINARIO NACIONAL E INTERNACIONAL DE ESPECIES PROMISORIAS, 2003, Medelin. Anais...p.10.

SANABRIA, H. L.; GARCÍA, M.; DÍAZ, H.; MUNOZ, J.E. Caracterización molecular con marcadores RAM de arboles nativos de Psidium guajava (guayaba) en el Valle del Cauca. Acta Agronomica, Colombia, v. 55, p. 27-38, 2006.

SANTOS, C. A. F.; CUNHA E CASTRO, J. M.; SOUZA, F. F.; VILARINHO, A. A.; FERREIRA, F. R.; PÁDUA, J. G.; BORGES, R. M. E.; BARBIERI, R. L.; SOUZA, A. G. C.; RODRIGUES, M. A. Preliminary characterization of Psidium germplasm in different Brazilian eco-geographic regions. Pesquisa Agropecuária Brasileira, Brasília, v. 43, p. 437-440, 2008a.

SANTOS, C. A. F.; OLIVEIRA, V. R.; KILL, L. H. P.; SÁ, I. I. S. Variabilidade genética com base em marcadores RAPD de três espécies arbóreas ameaçadas de extinção no Semiárido brasileiro. Scientia Forestalis, Piracicaba, v. 74, p. 37-44, 2007.

SANTOS, C. A. F.; RODRIGUES, M. A.; ZUCCHI, M. I. Variabilidade genética do umbuzeiro no Semiárido brasileiro por meio de marcadores AFLP. Pesquisa Agropecuária Brasileira, Piracicaba, v. 43, p. 1037-1043, 2008b.

SÃO JOSÉ, A. R. et al. Cultivo de goiabeira no Brasil. In: PRIMER SIMPOSIO INTERNACIONAL DE LA GUAYABA, 1., 2003, Aguascalientes. Memoria... p. 84-115.

SOARES-SILVA, L. H.; PROENÇA, C. E. B. A new species of Psidium L (Myrtaceae) from southern Brazil. Botanical Journal of the Linnean Society, London, v.158, p. 51-54, 2008.
SÃO JOSÉ, A. R.; REBOUÇAS, T. N. H.; DIAS, N. O.; HOJO, R. H.; BOMFIM, M. P. Cultivo de goiabeira no Brasil. In: PRIMER SIMPOSIO INTERNACIONAL DE LA GUAYABA, 1., 2003, Aguascalientes. Memoria... p. 84-115.

SOARES-SILVA, L. H.; PROENÇA, C. E. B. A new species of Psidium L (Myrtaceae) from southern Brazil. Botanical Journal of the Linnean Society, London, v.158, p. 51-54, 2008.

SOUZA, R. M.; NOGUEIRA, M. S.; LIMA, I. M.; MELARATO, M.; DOLINSKI, C. M. Manejo de nematoides das galhas da goiabeira em São João da Barra (RJ) e relato de novos hospedeiros. Nematologia Brasileira, Campinas, v. 30, n. 2, p. 165-169, 2006.

VALDÉS-INFANTE, J.; BECKER, D.; RODRIGUEZ, N.; VELAZQUEZ, B.; GONZALEZ, G.; SOURD, D.; RODRIGUEZ, J.; RITTER, E.; ROHDE, W. Molecular characterization of Cuban accessions of guava (Psidium guajava $\mathrm{L}$ ) establishment of a first molecular linkage map and mapping of QTLs for vegetative characters. Journal of Genetics of Breeding, Rome, v. 57, p. 349 358, 2003.

VALDÉS-INFANTE, J.; RODRIGUÉZ, N. N.; BECKER, D.; VELÁSQUEZ, B.; SOURD, D.; ESPINOSA, G.; ROHDE, W. Microsatellite characterization of guava (Psidium guajava $\mathrm{L}$ ) germplasm collection in Cuba. Cultivos Tropicales, La Habana, v. 28, n. 3, p. 61-67, 2007.

WATSON, L.; DALLWITZ, M. J. The families of flowering plants: descriptions, illustrations, identification, and information retrieval. 1992 onwards. Version: 20th May 2010. Disponível em: $<$ http://delta-intkey.com>. Acesso em: 03 jun. 2010.

WRIGHT, S. The genetical structure of populations. Annals of Eugenics, London, v.15, p.395-420, 1951. 